\title{
On the Road of Excellence
}

\author{
Robert B Kalina, Publisher
}

\begin{abstract}
A
s a publisher, I would like nothing more than to take credit for the success of The Canadian Journal of Gastroenterology. My contribution, however, pales in comparison with that of the Editors-in-Chief over the past 19 years.

Drs Thomson and Williams' work in starting up this journal was enormous and they continued until it evolved into a highquality, world-class journal. Dr Lloyd Sutherland was appointed as the second Editor-in-Chief in 2000. As a clinical trials expert, he was able to elevate the Journal to yet another level, increasing both its quality and prominence. This prominence was reflected by an increase in the impact factor, placing the Journal in the top one-half of the main gastroenterology publications. This was a considerable feat for a relatively young journal, published in a country with a relatively small population and competing with the giant next door.

Nevertheless, the most significant role the Journal has played is not in its international profile but in its effect on Canadian research. In addition to being a well-recognized
\end{abstract}

journal, The Canadian Journal of Gastroenterology has successfully fulfilled its role as a truly national journal, not only by opening the window on Canadian research to the world, but also by providing Canadian researchers with a vehicle for the dissemination of their research to a wide body of Canadian physicians.

This issue establishes a new Editor-in-Chief - Dr Paul Adams, Professor of Medicine and Chief of Gastroenterology at the London Health Sciences Centre, University of Western Ontario, London, Ontario.

We are confident that Dr Adams' tenure will move the Journal even more in the forward direction. In his first few months, he has made it his goal to work with us to establish The Canadian Journal of Gastroenterology as the first Pulsus journal to use the Pulsus Group online review system.

We wish Dr Adams all the best during his five-year tenure and look forward to working with him on taking the Journal to an even higher level of excellence. 


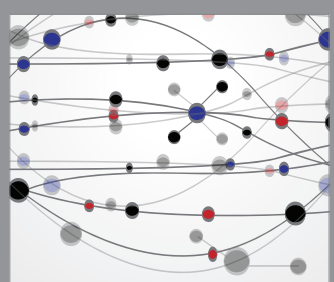

The Scientific World Journal
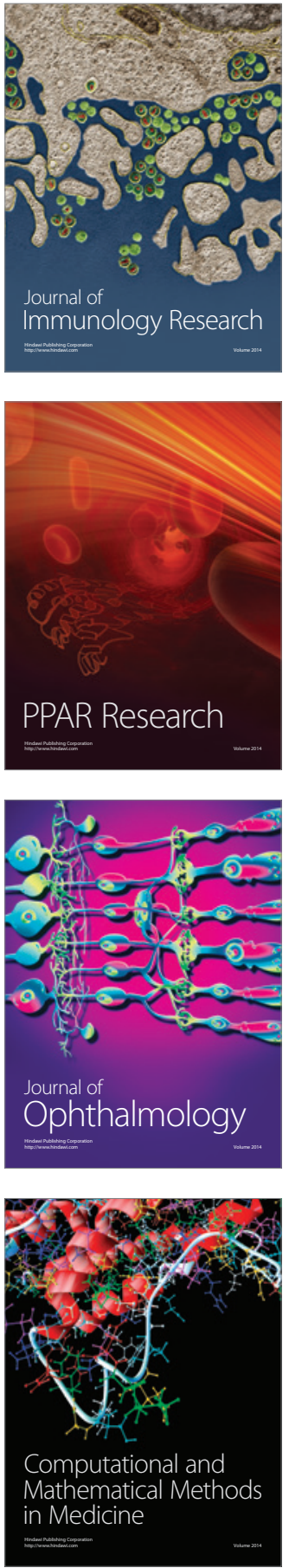

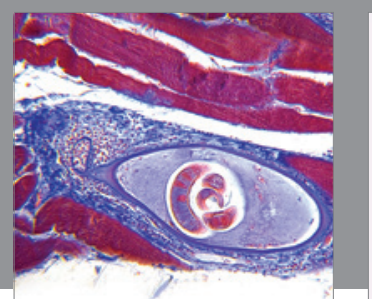

Gastroenterology Research and Practice

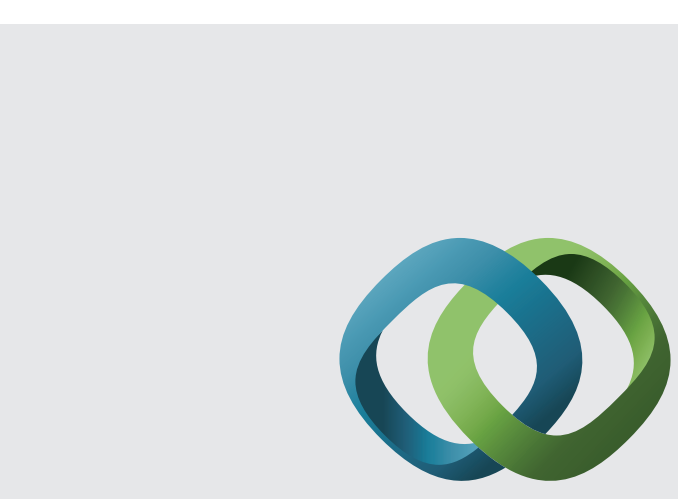

\section{Hindawi}

Submit your manuscripts at

http://www.hindawi.com
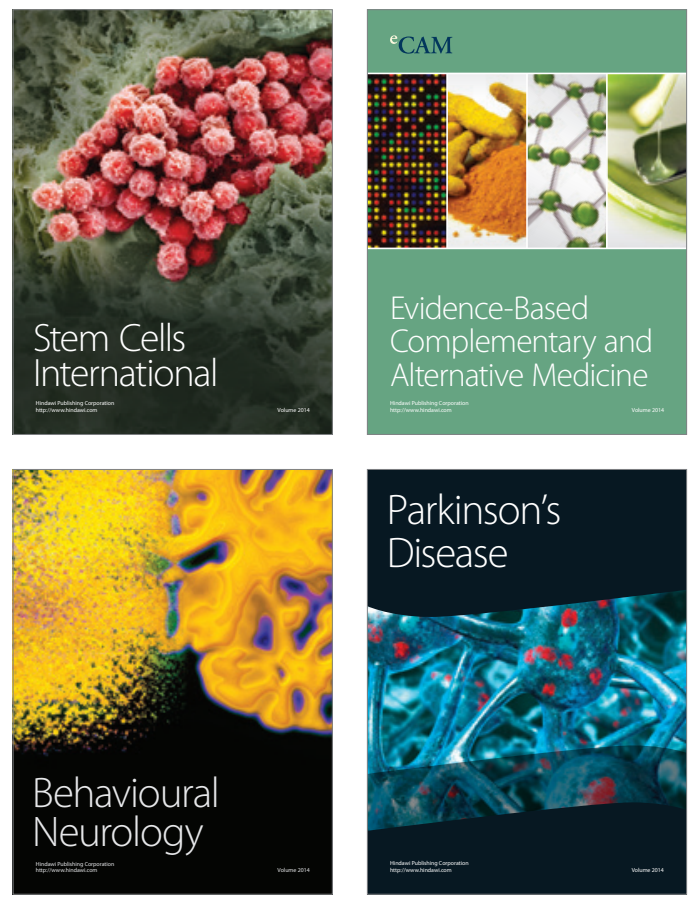
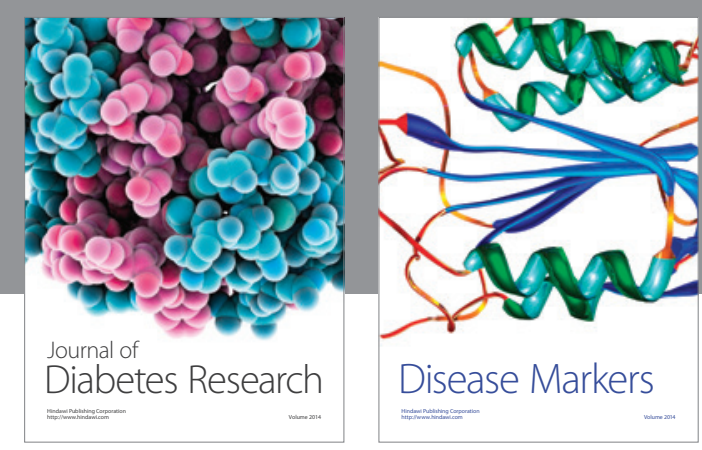

Disease Markers
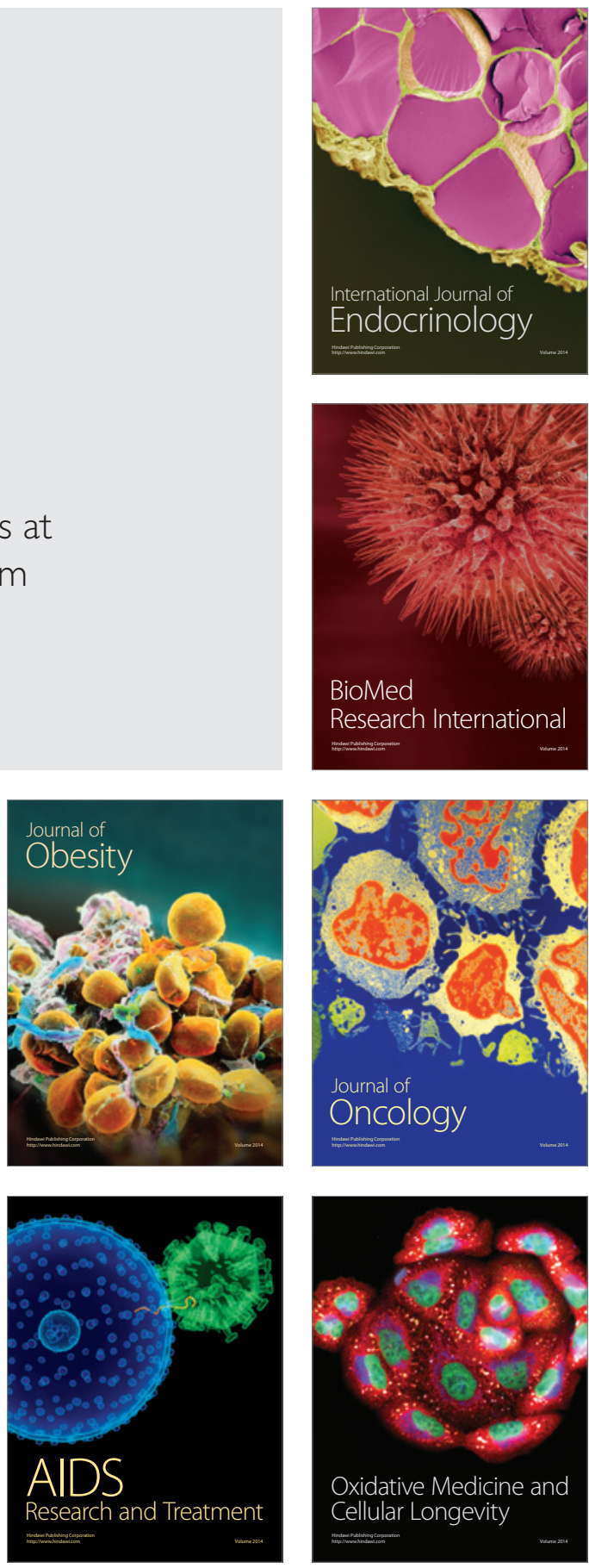